\title{
COHERENCIA, JUSTIFICACIÓN Y DERECHO. RESPUESTA A LOS PARTICIPANTES
}

Agradezco enormemente la oportunidad de poder discutir mi trabajo sobre coherencia en el foro de Discusiones. Los trabajos de Manuel Atienza, Juliano Maranhão, Cristina Redondo, Aldo Schiavello, Guillermo Lariguet y Claudio Michelon abordan, desde distintas perspectivas, aspectos centrales de la teoría coherentista y sacan a la luz importantes conexiones entre el coherentismo y algunas cuestiones iusfilosóficas fundamentales, tales como el problema del conflicto normativo, la relación entre lógica y epistemología jurídica, la relevancia del concepto de virtud para el derecho y cuestiones (siempre vigentes) acerca de la objetividad y la racionalidad en el Derecho. Estoy muy agradecida a los participantes por el 
esfuerzo dedicado a discutir en tanto detalle mi texto; sus críticas y sugerencias me han obligado a ahondar en la reflexión acerca de algunos de los problemas fundamentales que plantea el coherentismo en el Derecho y, en concreto, la aproximación al mismo que he tratado de desarrollar en los últimos años y que he presentado de forma resumida en el artículo objeto de comentario en este número. Continúo, en lo que sigue, la conversación acerca de algunos de estos problemas.

\section{Respuesta a Manuel Atienza. Los límites de la COHERENCIA}

En su generosa introducción, Atienza plantea una (larga) lista de preguntas (difíciles) en relación a cada una de las tesis que defiendo en mi artículo. Me centraré en la cuestión que más preocupa a Atienza: el papel de la coherencia en una teoría de la racionalidad. Al hilo de discutir esta cuestión, trataré de dar respuesta a algunos de los interrogantes que formula Atienza.

La objeción principal de Atienza, como él mismo señala, es una objeción de carácter metodológico, más que substantivo: en mi propuesta, el concepto de coherencia se amplía tanto como para hacerlo coincidir prácticamente con el de racionalidad. Sin duda, el concepto de coherencia como satisfacción de restricciones que adopto en mi trabajo es mucho más amplio que algunas concepciones alternativas de coherencia, ya que integra relaciones deductivas, analógicas, explicativas, etc. dentro del cómputo de la coherencia. Sin embargo, a diferencia de lo que sostiene Atienza, en mi propuesta no se reduce la racionalidad a la coherencia. De hecho, la teoría de la coherencia óptima parte de la idea de que el razonamiento de tipo coherentista no puede, por sí sólo, conferir justificación, sino que es necesario suplementar los criterios de coherencia con criterios de responsabilidad epistémica. Por lo tanto, en mi propuesta, la racionalidad no es exclusivamente una cuestión de coherencia, sino que la virtud de los agentes constituye un estándar fundamental para evaluar la racionalidad de las decisiones y de las creencias tanto acerca de los hechos como del derecho. La virtud 
juega pues un papel central en la concepción de la racionalidad que subyace a la concepción coherentista de la justificación jurídica defendida en mi trabajo.

Además, tampoco me parece que la coherencia -ni siquiera aquélla que resulta de un proceso de razonamiento virtuoso- sea el único elemento relevante en una teoría de la racionalidad. Hay una diversidad de cuestiones que caen dentro del ámbito de aplicación de una teoría de la racionalidad y que, a mi modo de ver, no se pueden abordar exclusivamente en términos de coherencia. Algunas de estas cuestiones aparecen, de una u otra manera, en el ensayo de Atienza, de modo que aprovecho aquí para contestar algunas de sus preguntas.

Un primer grupo de problemas que no se pueden atacar apelando exclusivamente a la coherencia son los problemas relativos a la racionalidad legislativa. Aunque, desde luego, me parece necesario investigar la cuestión de qué papel juega la coherencia en la legislación, en mi trabajo me he centrado, como es habitual en la teoría del derecho contemporánea, en la perspectiva del juez. En todo caso, me parece que la coherencia, y en esto coincido con Atienza, tiene una función mucho más limitada en la justificación de una ley que en la justificación de una decisión judicial. La coherencia es, sin duda, uno de los elementos que contribuyen a la racionalidad legislativa, pero la misma depende de diversos factores. El análisis de Atienza según el cual es posible diferenciar entre cinco niveles de racionalidad distintos para evaluar la legislación (linguiística, jurídico-formal, pragmática, teleológica y ética) me parece un punto de partida muy atractivo para abordar la cuestión de la justificación de la legislación ${ }^{1}$. Aunque la coherencia juega un papel fundamental en dicha justificación -a nivel, desde luego, jurídico-formal, pero también a otros niveles, como el pragmático y el ético- el alcance de los argumentos de coherencia en una teoría de la legislación es menor que en el caso de la argumentación judicial.

La concepción de la coherencia como satisfacción de restricciones -y contesto aquí otra de las cuestiones planteadas por

${ }^{1}$ M. Atienza, “Contribución para una teoría de la legislación”, Doxa 6 (1989). 
Atienza en relación a la tesis 1 de mi trabajo- me parece que puede ser útil para dar cuenta del tipo de coherencia que es relevante para la justificación de la legislación. Al igual que en el caso de la coherencia fáctica y normativa, sería necesario determinar los elementos y las restricciones así como los tipos de coherencia relevantes. La sugerencia de Thagard según la cual es posible entender los problemas morales y políticos como problemas que requieren la integración de coherencia deductiva, explicativa, analógica y deliberativa me parece un buen punto de partida para iniciar una reflexión acerca de la función que cumplen los argumentos de coherencia en la justificación de la legislación.

Un segundo grupo de cuestiones que caen dentro del ámbito de una teoría de la racionalidad y para las cuales la coherencia es una herramienta útil, pero de alcance limitado, son las relativas a la evaluación de los procesos de descubrimiento. Como he señalado en mi trabajo, la coherencia juega un papel importante en la generación de hipótesis y pruebas en el contexto de descubrimiento. Por un lado, tiene un papel negativo, en cuanto que nos permite reducir el conjunto de hipótesis que vale la pena considerar a una serie manejable de teorías que son mínimamente compatibles con el conjunto de creencias aceptadas acerca de los hechos y del derecho. Por otro lado, la coherencia también juega un papel positivo, ya que consideraciones de coherencia nos llevan a formular hipótesis que mejor explican las pruebas o los datos disponibles y orientan la investigación motivando la búsqueda de pruebas y datos que apoyen hipótesis consideradas como plausibles. La coherencia es además un instrumento fundamental para organizar las ideas y las pruebas relevantes en una investigación de manera efectiva. Como Schum y Tillers han mostrado, en el ámbito del razonamiento jurídico acerca de los hechos, el éxito de una investigación depende, de manera fundamental, de que los datos disponibles se conecten de manera adecuada $^{2}$. Algunos de los mecanismos más importantes para organizar

\footnotetext{
${ }^{2}$ Véase, P. Tillers y D. A. Schum, "A Theory of Preliminary Fact Investigation", U. C. Davis Law Review 24 (1991); P. Tillers y D. A. Schum, "Marshalling Evidence for Adversary Litigation", Cardozo Law Review 12 (1991); D. A. Schum, The Evidential Foundations of Probabilistic Reasoning. Evantston: Northwestern University Press, 199, pp. 489-504 y D. A. Shum, "Marshalling
} 
las pruebas, tales como los 'escenarios', los 'schemata' y las 'teorías del caso' se basan en estrategias coherentistas. La coherencia, por lo tanto, también cumple una función importante en la etapa de organización de pruebas e ideas que es central en los procesos de descubrimiento.

Ahora bien, huelga decirlo, la racionalidad de los procesos de descubrimiento depende de una variedad de factores que no se pueden reducir a argumentos de coherencia. Para empezar, la incoherencia es también un motor importante en el contexto de descubrimiento ${ }^{3}$. Y, por supuesto, patrones de razonamiento deductivo e inductivo juegan también una función importante en la generación de hipótesis prometedoras y en el descubrimiento de pruebas o datos relevantes. No pretendo (y respondo aquí a algunas de las preguntas que me hace Atienza en relación a la tesis 2 de mi trabajo) reducir la inducción a la abducción: ambas formas de inferencia contribuyen de manera distintiva -proporcionando generalizaciones inductivas y explicaciones, respectivamente- a expandir el conocimiento ${ }^{4}$.

En tercer lugar, la coherencia juega, como he sostenido en mi trabajo, un papel importante en la deliberación acerca de fines, pero no me parece que se pueda reducir el razonamiento acerca de fines al razonamiento coherentista. Atienza escribe lo siguiente (en su crítica a la tesis 6 de mi trabajo): “¿Es razonable pensar que la deliberación sobre fines está exclusivamente -o esencialmente- guiada por alguna idea de coherencia? Yo no dudo que la coherencia juega aquí un papel, pero para deliberar acerca de fines antes hay que determinar cuáles son esos fines y no veo que eso sea una función de la teoría de la coherencia". A diferencia de lo que sostiene Atienza, no me parece que la coherencia sea irrelevante cuando se trata de determinar qué fines son valiosos. La idea

Thoughts and Evidence during Fact Investigation", South Texas Law Review 40 (1999).

${ }^{3}$ Volveré sobre este punto en mi réplica al comentario de Guillermo Lariguet.

${ }^{4}$ Véase Flach y Kakas, "Abduction and Induction: Some Background Issues", P.A. Flach y A. C. Kakas, eds., Abduction and Induction. Dordrecht: Kluwer, 2001, pp. 1-27.

${ }^{5}$ M. Atienza, “¿Coherencia o racionalidad?”, p. 18. Énfasis añadido. 
de que el razonamiento práctico sólo discurre una vez que los fines han sido determinados me parece que es una idea que resulta de la combinación de una concepción lineal de inferencia -propia del fundacionismo- y una concepción instrumental de razonamiento práctico, que toma como punto de partida de cualquier inferencia práctica un conjunto de fines y valores, cuya determinación cae fuera del ámbito de una teoría del razonamiento. Como es bien sabido, uno de los elementos centrales del coherentismo es una concepción holista de inferencia, alternativa a la concepción lineal de inferencia que está en la base del fundacionismo. En una concepción coherentista, la determinación de qué fines son valiosos no es un paso previo al razonamiento acerca de los mismos: uno delibera acerca de qué hacer en el caso concreto a la vez que uno delibera acerca de fines y valores. "Trabajamos -como dijo Rawls- desde los dos extremos", ninguno de ellos tiene, en este sentido, un lugar fundacional y, por supuesto, ninguno de ellos -a diferencia de lo que sostiene el instrumentalismo- está fuera del ámbito de la razón 6 .

Esto no implica, sin embargo, que todo el razonamiento acerca de fines, incluida la determinación de los mismos, sea una cuestión de coherencia. Cuando tratamos de determinar qué fines son valiosos, la coherencia juega un papel importante, en cuanto que nos permite, por ejemplo, rechazar ciertos fines y valores en aras de su incoherencia con un conjunto de fines y valores aceptados como valiosos; especificar el contenido de fines y valores que están, en el caso concreto, en conflicto; o designar un fin como valioso por razones de coherencia con el conjunto de juicios particulares y principios generales considerados como justificados. Pero las inferencias coherentistas no son el único tipo de inferencias que son operativas en la deliberación acerca de fines y valores. La deducción juega un papel, obviamente, central también en el razonamiento acerca de fines y valores. La inducción (práctica) es esencial para poder aprender de la experiencia qué consideramos valioso o importante ${ }^{7}$. Y que todo el razonamiento práctico no se pueda reducir

\footnotetext{
${ }^{6}$ J. Rawls, Teoría de la justicia. México: Fondo de Cultura Económica, 1995, p. 38.

7 Para un lúcido análisis de la inducción práctica, veáse E. Millgram, Practical Induction. Cambridge: Harvard University Press, 1997.
} 
a inferencias medio-fin no implica que estas inferencias no sean, desde luego, importantes. Hay, por lo tanto, una variedad de patrones de inferencia mediante los cuales se puede llegar a alcanzar decisiones, planes, juicios acerca de qué hacer, evaluaciones, acciones, etc. justificadas.

En resumen, hay límites importantes a lo que es posible avanzar en la dirección de la racionalidad, tanto en el contexto del razonamiento teórico como práctico, usando mecanismos coherentistas. La teoría de la legislación, el contexto de descubrimiento y el del razonamiento acerca de fines y valores, son algunos de los ámbitos en los que los límites de la coherencia son particularmente visibles. Otro contexto en el que la coherencia tampoco nos permite justificar satisfactoriamente una decisión son los casos dilemáticos -y contesto aquí otra de las preguntas que plantea Atienza en relación a la tesis 6 de mi trabajo. Como argumentaré en detalle más adelante, la teoría de la coherencia no nos deja desamparados frente a estos casos, aunque los mismos son, desde luego, casos límite para una teoría coherentista (incluso para una teoría coherentista suplementada con una teoría de la virtud)- quizá, como dice Lariguet, estos casos no sólo sean casos límite para la teoría de la coherencia, sino también para una teoría de la racionalidad $^{8}$.

Ahora bien, aunque la teoría de la racionalidad no se puede (no se debe) reducir a la teoría de la coherencia, la coherencia es, no obstante, como espero haber mostrado en mi trabajo, un elemento indispensable en una teoría de la racionalidad. Si esto es así, entonces, las aproximaciones formalistas a la racionalidad -que aspiran a explicar la racionalidad apelando a las reglas de la lógica, la probabilidad, etc. y otras herramientas formales- no parecen viables. Estas teorías evalúan la racionalidad de las creencias y las acciones con independencia del contenido de las mismas, de su etiología, del contexto de evaluación y de los agentes y aunque, por supuesto (y contesto aquí a algunas de las

\footnotetext{
${ }^{8}$ G. Lariguet, "Los dilemas morales qua límites de la racionalidad práctica", Diánoia 55 (2010).
} 
preguntas formuladas por Atienza en relación a mis tesis 4, 5 y 10), la sensibilidad al contexto, el punto de vista del agente y la responsabilidad epistémica del mismo en la formación de creencias y en los procesos de toma de decisión no sean elementos exclusivos del coherentismo, sí que son, como he argumentado, elementos centrales en esta teoría. El coherentismo se opone así a los distintos intentos -dentro y fuera del Derecho- por desarrollar concepciones 'algorítmicas' de la racionalidad, sin que esto implique abrazar ninguna tesis nihilista o escéptica acerca de la razón.

Pero, se pregunta Atienza (en su comentario a la tesis 8) "¿no podría decirse que el intento de encontrar una vía media entre el formalismo y el escepticismo es una característica de todas las teorías de la racionalidad práctica, esto es, de todos aquéllos que sostienen una concepción amplia de la racionalidad? Sin ir más lejos, ¿no era ésa la pretensión de Perelman y de todos los autores que integran lo que se suele llamar 'teoría estándar de la argumentación jurídica? ¿Habría que considerar también como coherentistas a todas estas teorías? ¿No se estará identificando aquí demasiado rápidamente coherencia con racionalidad o racionalidad práctica?" $\mathrm{El}$ coherentismo, por supuesto, no es la única alternativa no escéptica al formalismo. No me parece que se pueda identificar la coherencia con la racionalidad práctica de manera que todas las teorías (no formalistas) de racionalidad práctica sean versiones del coherentismo. El coherentismo es una opción teórica distintiva, dentro del conjunto de teorías que sostienen una concepción amplia de racionalidad.

Consideremos, por ejemplo, la teoría de la ponderación de Alexy -y aprovecho aquí para contestar la pregunta de Atienza, en su crítica a la tesis 6 , acerca de si existe una diferencia substancial entre dicho método y el coherentista- ${ }^{10}$. Las posturas coherentistas acerca de cómo resolver los casos de conflictos normativos -como la propuesta de

\footnotetext{
${ }^{9}$ M. Atienza, ¿Coherencia o racionalidad?”, p. 19.

${ }^{10}$ R. Alexy, "On Balancing and Subsumption: A Structural Comparison”, Ratio Iuris 16 (2003).
} 
Hurley o el especificacionismo de Richardson- se apartan de la teoría de la ponderación defendida por Alexy en varios puntos fundamentales. Para empezar, la teoría de Alexy, a diferencia de las teorías coherentistas, asume que los valores morales son conmensurables así como, y esto es esencial, que tal conmensurabilidad es un requisito para la elección racional. Además, la propuesta de Alexy adopta, como es bien sabido, un marco cuantitativo para abordar las cuestiones de conflicto normativo en el ámbito del derecho que es contraria a la concepción coherentista, cualitativa, de razonamiento práctico. Por último, mientras que en la teoría de la ponderación de Alexy la corrección de una decisión depende, en último término, de que la misma maximice un valor o conjunto de valores, el coherentismo sostiene que son consideraciones de coherencia, y no de eficacia, las que deben regir el proceso deliberativo.

Por lo tanto, el coherentismo es una de las vías posibles para la articulación de una teoría amplia de la racionalidad práctica, distinta de otras alternativas teóricas. No obstante, hay, me parece, buenas razones para adoptar si no el coherentismo tout court sí, al menos, una teoría del razonamiento práctico que le otorgue un papel fundamental a la noción de coherencia. No repetiré aquí los distintos argumentos a favor de una teoría coherentista que ya he expuesto en mi trabajo, pero sí quisiera enfatizar dos de las razones (mencionadas por Atienza en su discusión de las tesis 3 y 9) que hacen que el coherentismo sea una teoría del razonamiento jurídico, al menos en principio, atractiva: la plausibilidad psicológica y la adecuación descriptiva de esta teoría. El coherentismo es una teoría plausible desde un punto de vista psicológico y cercana a la práctica argumentativa y, por ello, esta teoría está bien situada para orientar, guiar y mejorar la práctica jurídica. Esto le da una ventaja comparativa respecto a otras teorías de la racionalidad práctica que plantean ideales cuya implementación es imposible, dados nuestros recursos cognitivos y que son ajenos a las formas ordinarias de razonar en contextos jurídicos ${ }^{11}$.

${ }^{11}$ La teoría bayesiana de la decisión racional es un ejemplo paradigmático de teorías de la racionalidad altamente idealizadas. 
En conclusión, la coherencia no resuelve la diversidad de problemas propios de una teoría de la racionalidad. La vida racional no termina con la coherencia, pero sin ella, no es posible, me parece, iniciarla. La búsqueda de coherencia es, en este sentido, constitutiva de la 'precaria' vida de los animales racionales: la coherencia (al igual, dicho sea de paso, que la racionalidad misma) es una herramienta limitada, pero cierto grado de coherencia es necesario para la racionalidad $^{12}$. Dijo Alexy (en la defensa de mi tesis doctoral, después de una sesión maratoniana de preguntas y justo antes de lanzar una nueva batería de objeciones...) que 'ninguna pregunta debe quedar sin respuesta'. No pretendo, huelga decirlo, haber dado respuesta en mi réplica a todas las preguntas de Atienza. Como he tenido el privilegio de constatar a lo largo de muchos años, Atienza tiene la habilidad de identificar certeramente los problemas fundamentales, los puntos de mayor alcance y los flancos más débiles de cualquier postura y argumento. En esta ocasión, como suele ocurrir, me temo que muchas de sus preguntas, pace Alexy, han de quedar, al menos por el momento, sin contestar...

\section{Respuesta a Juliano Maranhão. Coherencia y FIDELIDAD AL DERECHO}

En su comentario, Maranhão avanza una propuesta muy detallada acerca de cómo caracterizar la actitud conservadora que está implícita en una epistemología coherentista y, de manera más específica, en una teoría coherentista de la justificación de las proposiciones normativas en el Derecho. Maranhão, más que objetar a mi propuesta coherentista, se pregunta si la misma está o no en desacuerdo con las tesis expuestas en su comentario. En lo que sigue, trataré de determinar los puntos de acuerdo y desacuerdo entre el análisis de Maranhão y el expuesto en 'Diez Tesis'. En el curso de examinar las posibles

${ }^{12}$ La frase es de Fogelin. Vid. R. Fogelin, The Tightrope of Reason: The Precarious Life of a Rational Animal. Cambridge: Oxford University Press, 2003. 
diferencias entre ambas propuestas, trataré de clarificar el sentido en el que, a mi parecer, una epistemología coherentista es una epistemología conservadora.

Empecemos por formular las tesis principales que Maranhão defiende en su comentario. Las tesis son las siguientes: 1. La base de la coherencia consiste en un conjunto de normas identificadas como jurídicas y un conjunto de casos claros explicables por dichas normas; 2. Los principios jurídicos son el producto de una inferencia a la mejor explicación de los objetivos y valores protegidos por el conjunto relevante de normas jurídicas que constituyen dicha base; 3 . Son dos los tipos fundamentales de inferencias abductivas mediante las cuales se puede construir una interpretación coherente de la base: la expansión y la contracción; 4. La base se debe expandir para resolver casos 'novedosos', es decir, casos para los que la base no proporciona una solución; 5. La base se debe contraer para resolver casos 'anómalos', es decir, casos en los que la solución derivada de la base es inconsistente con la que se sigue de los principios que mejor explican la misma; 6. La clausura coherentista del sistema jurídico mediante operaciones de expansión y de contracción se rige por una actitud conservadora; 7. En relación a la expansión, la actitud conservadora exige que la modificación de la base sea mínima, es decir, que sólo se añada lo necesario para derivar una solución para el caso novedoso y que la misma sea idéntica a la que proporcionan los principios jurídicos que mejor explican la base original; 8 . En relación a la contracción, la actitud conservadora exige que las modificaciones a la base original se limiten a especificar las condiciones de aplicación de aquellas normas que están en conflicto con el conjunto de principios que mejor explica la base original; 9. Una solución normativa a un caso novedoso o anómalo está epistémicamente justificada si el agente selecciona (en base a criterios de coherencia) el conjunto de principios que mejor explican la base original así como la mejor expansión (o contracción) de la misma (entre las mínimas) de manera epistémicamente responsable; 10. La 'fidelidad' a la base original es una presuposición de una epistemología jurídica coherentista. 
El análisis (y la formalización) de Maranhão de la actitud conservadora que presupone una epistemología coherentista contribuye de manera importante a la literatura coherentista. Aunque la relación entre coherencia y conservadurismo es un punto central en la teoría coherentista de la justificación así como en las críticas a la misma, la discusión (incluyendo, desde luego, la mía) carece del detalle y la precisión con la que Maranhão trata esta cuestión. Hay mucho en común entre la propuesta defendida por Maranhão y mi teoría coherentista. En primer lugar, coincido con Maranhão en considerar que los principios jurídicos son el producto de una inferencia a la mejor explicación (tesis 2). Como he defendido en 'Diez Tesis' (y, en más detalle, en The Tapestry of Reason) ${ }^{13}$, lo que llamo elementos normativos (precedentes, normas jurídicas generales, normas jurídicas específicas, etc.) juegan en el Derecho un papel similar al papel que juegan las observaciones en las ciencias, al proporcionar 'evidencia' para las distintas hipótesis interpretativas, de manera análoga al modo en el que las observaciones son evidencia para hipótesis explicativas. Hay una diferencia, sin embargo, entre ambas propuestas en cuanto a cómo se relacionan las hipótesis interpretativas y los elementos normativos y, en concreto, al lugar que ocupan los principios en el razonamiento coherentista. Mientras que para Maranhão los principios no forman parte del explanandum de las inferencias coherentistas, es decir, no son parte de la base de la coherencia (tesis 1), la teoría coherentista que he tratado de avanzar acepta la tesis según la cual la relación de coherencia es una relación simétrica y, por lo tanto, existe una relación de soporte mutuo entre los elementos normativos y las hipótesis interpretativas que forman parte de un conjunto coherente. En este sentido, los principios y valores que mejor explican las reglas y los casos son también parte de la base de coherencia. En segundo lugar, comparto plenamente con Maranhão la aproximación localista y contextualista a la individualización de la base de la coherencia, frente a propuestas globales que carecen, como señala Maranhão, de plausibilidad psicológica (entre otros problemas). En tercer lugar, la propuesta de Maranhão, como la mía, le otorga a la

\footnotetext{
${ }^{13}$ A. Amaya, The Tapestry of Reason: An Inquiry into the Nature of Coherence and its Role in Legal Argument. Oxford: Hart Publishing, en prensa (2012).
} 
responsabilidad epistémica un papel clave en una epistemología coherentista (tesis 9). Por último, también como Maranhão, sostengo que la literatura sobre revisión de creencias es de gran ayuda para clarificar la manera en la que funciona la inferencia coherentista -complementada con la concepción de la coherencia como satisfacción de restricciones, punto que también acepta Maranhão. Hay, por lo tanto, un acuerdo importante entre ambas propuestas en cuanto a los rasgos distintivos generales de una epistemología coherentista: la adopción de un marco explicativo, responsibilista, local y contextual, y el uso de formalismos tales como el desarrollado para modelar la revisión de creencias (así como de teorías semi-formales, como la propuesta por Thagard).

No obstante, hay diferencias significativas entre ambas propuestas en relación a cómo debe entenderse el conservadurismo que caracteriza la epistemología coherentista. En primer lugar, hay una diferencia importante en relación a los mecanismos mediante los cuales se puede restaurar la coherencia. Maranhão sostiene que son dos las operaciones fundamentales que llevan a obtener la coherencia, a saber, la expansión conservadora y la contracción conservadora (tesis 3). La contracción no consiste, según Maranhão, en la eliminación de alguno de los elementos de la base original sino en su especificación o cualificación (tesis 8). A diferencia de Maranhão, en mi propuesta son tres los mecanismos de construcción de coherencia: expansión, es decir, la adición de nuevos elementos, revisión (o re-interpretación), que coincide en lo esencial con la contracción conservadora caracterizada por Maranhão, y contracción propiamente dicha, es decir, la eliminación de elementos de la base original. En algunos casos, es, por lo tanto, necesario, en aras de obtener un conjunto coherente, la eliminación (y no la mera re-interpretación) de elementos disonantes -por ejemplo, considerando como erróneo un precedente que está en conflicto con principios aceptados como justificados. En este sentido, mi propuesta es menos conservadora que la avanzada por Maranhão.

En segundo lugar, la operación de expansión tiene un mayor alcance en mi propuesta que en la de Maranhão. Para Maranhão la 
expansión consiste en la adición de nuevas reglas a la base original para solucionar casos novedosos (tesis 7). La sugerencia de ligar el uso de mecanismos de adición a la categoría de casos considerados (por analogía con las ciencias) como novedosos (y la de los mecanismos de contracción a los casos anómalos) me parece muy útil e iluminadora en cuanto que permite ser mucho más claro respecto del tipo de problemas (mas allá de su mera clasificación como casos difíciles) que ocasionan incoherencia y que motivan el uso de inferencias dirigidas al restablecimiento de la coherencia. Sin embargo, me parece que si restringimos, como hace Maranhão, la expansión a la adición de nuevas reglas, no es posible resolver de manera satisfactoria el reto que presentan los casos realmente novedosos. En ocasiones, me parece que es necesario expandir la base para incluir nuevos principios que den cuenta tanto de la base original como de los casos novedosos. En mi caracterización de la coherencia normativa, como he mencionado antes, los elementos son de dos tipos, hipótesis interpretativas y elementos normativos. Ambos -y no sólo los elementos normativos, a diferencia de lo que propone Maranhão- pueden ser modificados en aras de la coherencia. El restablecimiento de la coherencia puede requerir a veces (y, de manera central, en los casos novedosos y en los casos anómalos) la modificación (bien la expansión, bien la contracción, respectivamente) de principios. No sólo el conjunto de reglas y casos establecidos se pueden modificar, con el objetivo de alcanzar la coherencia, en base a los principios sino que también (y éste es un punto central para una teoría que sostiene, como la mía, que la relación de coherencia es una relación simétrica) los principios se pueden modificar en base a las reglas y al conjunto de casos relevante. Los casos novedosos pueden ser, desde una perspectiva coherentista, ocasiones para revisar de manera más importante el derecho que la modificación consistente exclusivamente en la adición de una nueva regla.

En tercer lugar, Maranhão requiere que los cambios introducidos para restaurar la coherencia sean mínimos (tesis 6). Sin embargo, cuán mínimos deban ser los cambios es una cuestión que, a mi parecer, no se puede decidir de antemano mediante la adopción de una regla que exija el mismo grado de conservadurismo para todos los casos. 
Creencias de segundo orden -de manera central, creencias acerca del peso que tienen las razones de autoridad- forman también parte de la base de la coherencia. Las razones de autoridad (en virtud del principio 4 de la teoría de la coherencia explicativa) tienen un papel privilegiado en la evaluación de la coherencia de las distintas hipótesis interpretativas. Sin duda, tales razones tienen que ocupar un papel preeminente en el razonamiento jurídico para que podamos hablar, con propiedad, de razonamiento jurídico. Pero dichas razones pueden no ser incluidas en el conjunto finalmente aceptado si hay fuertes razones de coherencia con otras consideraciones de carácter moral o político que así lo requieren. En último término, es el deliberador el que determina cuáles son los límites de la sistematización ${ }^{14}$. Para razonar correctamente acerca de cómo resolver un caso, y en esto Maranhão y yo estamos plenamente de acuerdo, no es suficiente con apelar a criterios de coherencia: es necesario que el deliberador aplique dichos criterios de manera epistémicamente responsable o virtuosa (tesis 9). Sin embargo, y en esto me aparto de manera fundamental de la postura defendida por Maranhão, la intervención de un agente virtuoso, no se limita a la selección de la mejor modificación, entre las mínimas, sino que la virtud es también necesaria para determinar, en el caso particular, si debe aceptarse la solución al caso que requiere menos modificaciones a la base original o si, por el contrario, es necesario introducir cambios más radicales $^{15}$.

En último término, y con esto concluyo, es una concepción diferente del papel que juega la virtud de la fidelidad en una teoría de las virtudes que debe poseer un agente jurídico la que distancia, de manera importante, mi propuesta de la de Maranhão. Para Maranhão, la fidelidad es una presuposición de una epistemología coherentista (tesis 10). Para que una decisión jurídica esté justificada, ésta debe, según Maranhão,

${ }^{14}$ H. Richardson, Practical Reasoning about Final Ends. Cambridge: Cambridge University Press, 1994, p. 179.

${ }^{15} \mathrm{O}$, incluso, si es preferible no introducir ninguna modificación por el momento y tolerar cierto grado de incoherencia. Véase G. Lariguet, "Todo lo que Ud. quería saber sobre la coherencia y no se atrevió a preguntarle a Amalia Amaya", p.117. 
cumplir dos condiciones: a) que la decisión satisfaga los requerimientos impuestos por la fidelidad, i.e., la actitud conservadora definida por la expansión y la contracción conservadoras; b) que el agente seleccione en base a criterios de coherencia las funciones 'maxichoice' que se usan en la construcción de las operaciones de expansión y contracción de manera epistémicamente responsable. Estas condiciones parecen estar ordenadas léxicamente: es necesario satisfacer la primera condición antes de que la segunda entre en juego ${ }^{16}$. Por lo tanto, según Maranhão, la fidelidad tiene un lugar prioritario en una teoría de las virtudes judiciales. Coincido con Maranhão en que la fidelidad, que yo definiría de manera, desde luego, menos precisa -pero también más flexiblecomo una 'actitud de respeto' hacia la base original, es decir, como una disposición a decidir un caso desde un 'punto de vista interno' ${ }^{17}$, es central en una teoría de las virtudes judiciales. Sin embargo, el alcance de esta virtud depende de los requerimientos de otras virtudes judiciales (tales como imparcialidad, la sobriedad, la justicia, etc.) con las que la virtud de la fidelidad puede entrar en conflicto. El juez virtuoso es, precisamente, aquél que tiene la habilidad de reconocer, en el caso concreto, qué es lo que la virtud requiere, a la luz de las distintas consideraciones que son relevantes en la situación particular ${ }^{18} \mathrm{El}$ manejo epistémicamente responsable o virtuoso de los criterios de coherencia, no siempre nos lleva a aceptar la solución normativa que requiere menos

\footnotetext{
${ }^{16}$ Acerca de la noción de orden léxico, véase J. Rawls, A Theory of Justice. Cambridge: Harvard University Press, 1999 (ed. rev.), pp. 37-38.

${ }^{17}$ Es decir, desde el punto de vista de un agente que acepta las normas que estructuran la deliberación jurídica y que está dispuesto a guiar su conducta por ellas. H. L. A. Hart, The Concept of Law. Oxford: Oxford University Press, 1994, pp. 88-91.

${ }^{18}$ A. Amaya, "Virtue and Reason in Law", en New Waves in the Philosophy of Law, editado por M. del Mar. New York: Palgrave-Macmillan, 2011. Esta concepción de juez virtuoso se basa, en gran parte, en la idea de virtud defendida por J. McDowell. Véase J. McDowell, "Virtue and Reason" en Mind, Value, and Reality, Harvard University Press, Cambridge, 1998. Véase también L. Zagzebski, Virtues of the Mind: An Inquiry into the Nature of Virtue and the Ethical Foundations of Knowledge, Cambridge University Press, Cambridge, 1996, pp. 219-231.
} 
modificaciones de la base original. A diferencia de lo que sostiene Maranhão, la virtud de la fidelidad no delimita el conjunto de las decisiones justificables. La asignación de tal prioridad a los requerimientos derivados de la fidelidad sería, en realidad, opuesto al espíritu de una epistemología coherentista.

\section{Respuesta a Cristina Redondo. Coherencia, LÓGICA Y EPISTEMOLOGÍA}

Los comentarios de Redondo se centran mayoritariamente en una serie de problemas que suscita la idea de inferencia coherentista que he defendido en 'Diez Tesis'. Los problemas serían los siguientes:

(i) La inferencia coherentista, entendida como una inferencia a la mejor explicación, dice Redondo, no compite ni con los esquemas de la lógica deductiva ni con los esquemas de la lógica inductiva, a diferencia de lo que parezco sostener, ya que mientras que la inferencia coherentista nos permite controlar la justificación de la acción de decidir (en todas sus fases, tanto del proceso como del producto), la inducción y la deducción son instrumentos que nos permiten controlar la justificación de los contenidos proposicionales involucrados en tales decisiones.

En efecto, estoy de acuerdo con Redondo en que la inferencia coherentista no compite ni con la inducción ni con la deducción. Mientras que la inferencia coherentista proporciona reglas de aceptación, es decir, nos permite aceptar ciertas conclusiones como justificadas, las reglas de la deducción y de la probabilidad (i.e., la lógica inductiva) no funcionan como reglas de aceptación, es decir, no nos dan razones para aceptar una determinada conclusión como justificada, sino que tan sólo ponen límites a lo que uno puede creer de manera consistente. La lógica deductiva nos permite determinar si ciertas conclusiones son o no consistentes con ciertas premisas, pero no ofrece ninguna guía acerca de qué premisas estamos justificados en 
aceptar. De manera similar, la lógica inductiva nos indica qué grado de probabilidad podemos asignar a ciertas proposiciones, a la luz de ciertas asignaciones previas de probabilidades, pero no nos permite evaluar la probabilidad inicial que se ha asignado a las mismas.

La diferencia entre la inducción y la deducción, por un lado, y la inferencia coherentista, por el otro, creo que se puede entender mejor a la luz de la distinción que traza Ramsey entre 'lógica formal' y 'lógica humana' o 'lógica de la verdad'19. Mientras que -dice Ramsey- la lógica formal, que incluye la lógica deductiva y el cálculo de probabilidades, tiene como objetivo asegurar que nuestras creencias no sean contradictorias, la lógica humana aspira a asegurar que nuestras creencias no sean simplemente consistentes entre sí, sino también con el mundo. A diferencia de la lógica formal, la lógica humana nos dice qué debemos creer si queremos alcanzar nuestros objetivos cognitivos $\mathrm{y}$, especialmente, el objetivo de tener creencias verdaderas. Mientras que la inferencia coherentista pretende regular qué estamos justificados en aceptar, a la luz de nuestros objetivos cognitivos, las inferencias deductiva e inductiva pretenden asegurar la consistencia (lógica y probabilística, respectivamente) de los contenidos proposicionales de nuestros sistemas de creencias. Es fundamental, por lo tanto, diferenciar, como bien indica Redondo, la lógica de la epistemología.

Ahora bien, el problema surge cuando se trata de derivar postulados epistemológicos de reglas lógicas. Impulsos formalistas han llevado a no pocos a tratar de reducir cuestiones acerca de qué es lo que uno debe creer a cuestiones que se pueden resolver exclusivamente mediante el uso de los sistemas lógicos (deductivos e inductivos), confundiendo la lógica 'formal' con la lógica 'humana' y tratando de construir una teoría de la racionalidad a partir de las reglas de la lógica deductiva o de la probabilidad. Tales intentos son moneda común en discusiones acerca de la racionalidad. En efecto, según la llamada teoría 'estándar' de la racionalidad, "ser racional es razonar conforme a

${ }^{19}$ F. P. Ramsey, 'Truth and Probability', en Philosophical Papers, editado por D.

H. Mellor. Cambridge: Cambridge University Press, 1990 (1926). 
principios de razonamiento basados en las reglas de la lógica, la teoría de la probabilidad, y reglas similares" ${ }^{20}$. Es decir, la teoría estándar de la racionalidad 'convierte' reglas de la lógica y la probabilidad en principios normativos de razonamiento. Estos impulsos formalistas no son, desde luego, ajenos al derecho. Basta pensar en los esfuerzos por reducir la justificación de la decisión judicial al silogismo o la justificación de las conclusiones acerca de los hechos al teorema de Bayes. Una concepción coherentista del razonamiento jurídico sí que se opone, firmemente, a estos impulsos formalistas.

Esto no significa que en dicha concepción no haya espacio para la lógica formal -deductiva o inductiva. El teorema de Bayes, por ejemplo, es extremadamente útil en el razonamiento probatorio en los casos, altamente frecuentes, en los que se presentan pruebas estadísticas. La deducción es fundamental, como he señalado en 'Diez Tesis', para evaluar la coherencia tanto de las hipótesis interpretativas como fácticas. De modo que la lógica nos proporciona, sin duda, herramientas útiles para justificar, en virtud de su coherencia, las premisas fáctica y normativa de la decisión judicial. Y, desde luego, y en esto concuerdo también plenamente con Redondo, la justificación interna de una decisión judicial es una cuestión que depende de que la misma pueda reconstruirse como una conclusión de una inferencia deductiva.

No hay, por lo tanto, incompatibilidad entre un modelo de inferencia coherentista y los sistemas de lógica formal. El coherentismo sí se enfrenta, sin embargo, tanto a los usos inapropiados (o 'imperialistas', como algunos los han calificado en el contexto del debate acerca de las aproximaciones bayesianas al razonamiento científico) $)^{21}$ de la lógica deductiva e inductiva así como a una concepción de inferencia que reduzca la misma a los patrones que se pueden captar mediante los sistemas de lógica formal. Es esta concepción limitada de inferencia la que se encuentra en la base de la crítica, que frecuentemente

${ }^{20}$ E. Stein, Without Good Reason: The Rationality Debate in Philosophy and Cognitive Science. Oxford: Clarendon Press, 1996, p. 5.

${ }^{21}$ J. Earman, Bayes or Bust? A Critical Examination of Bayesian Confirmation Theory. MIT Press, Cambridge, 1992, p. 1. 
se dirige en contra del coherentismo, según la cual el coherentismo carece de una concepción de inferencia y por ello no puede sino descansar, en último término, en la mera intuición. Pero una vez que superamos esta concepción formalista de inferencia, es posible mostrar que una teoría coherentista de la justificación cuenta con una sólida teoría de la inferencia. Es esta concepción reduccionista de inferencia la que está también en la base de otras críticas que se han dirigido en contra del coherentismo, como el problema de la circularidad, que paso ahora a examinar.

(ii) Redondo sostiene que si la coherencia es una relación de inferencia, entonces, es una relación vertical y asimétrica, es decir, una relación que se establece sólo en una dirección entre premisas y conclusión. Esta concepción de la coherencia, según Redondo, es problemática. Para empezar, entender la coherencia como una relación de inferencia genera un regreso al infinito ya que una determinada conclusión acerca de los hechos o del derecho estaría justificada si es la más coherente respecto de ciertos datos previamente aceptados, y la aceptación de éstos está justificada porque son los más coherentes respecto de un ulterior conjunto de datos, etc. Una solución a este problema es apelar a la noción tradicional en epistemología de proposiciones auto-justificadas, pero esta solución implica abandonar el coherentismo a favor del fundacionismo. Otra solución consiste en sostener que el regreso se cierra ya que las cadenas de justificación coherentista son circulares. Sin embargo, es dudoso que esta solución funcione, ya que incluso aunque el círculo sea lo suficientemente amplio y sólido, señala Redondo, puede que no sea más que una coherente ilusión. En pocas palabras, sostener que la coherencia es una relación inferencial nos lleva bien a abandonar el coherentismo o bien a aceptar círculos justificatorios que tenemos razones para sospechar que son viciosos.

Este problema, dice Redondo, no es una dificultad en especial para la concepción coherentista presentada en 'Diez Tesis', sino que afecta a todas las teorías de la coherencia. Además, hablar de 'inferencia coherentista' presenta un problema adicional y esta vez sí, específico, 
para mi teoría de la coherencia. Por un lado, la coherencia explicativa ocupa un lugar fundamental en la teoría que defiendo en mi trabajo y este tipo de coherencia consiste en una relación simétrica entre proposiciones, es decir, es una relación horizontal. Por otro lado, permanentemente se hace referencia a la coherencia como una relación de inferencia, es decir, asimétrica y vertical. Hay, por tanto, una 'ambigüedad', dice amablemente Redondo, en mi teoría en relación a la noción de coherencia o, directamente, diría yo, la teoría es inconsistente ya que sostiene simultáneamente que la coherencia es una relación inferencial y simétrica.

Empezaré por considerar la objeción que Redondo dirige, de manera específica, a mi propuesta. Sostener que la coherencia es una relación inferencial y simétrica no es inconsistente -ni siquiera ambiguo. La inconsistencia surge sólo si uno asume, como parece hacer Redondo, que las inferencias necesariamente son asimétricas, de manera que la justificación se transfiere de una proposición a otra de a través de una cadena de proposiciones ordenada por relaciones de prioridad epistémica. Pero esta concepción linear de inferencia, que está en la base de los sistemas de inferencia lógica, como ya sostuvo Bosanquet, no es la única concepción posible ${ }^{22}$. De hecho, un elemento central de las teorías coherentistas de la justificación es la idea de 'inferencia holista', es decir, una concepción de inferencia según la cual una proposición está justificada si pertenece a un sistema de proposiciones que se apoyan mutuamente ${ }^{23}$. En este sistema, por lo tanto, no hay una dependencia lineal entre las proposiciones, sino una relación de apoyo mutuo o recíproco. Esta concepción holística de inferencia es, como los sistemas informáticos conexionistas han puesto de manifiesto, computacionalmente efectiva $y$, lo que es quizá más importante, psicológicamente plausible: las inferencias (y, en concreto, las inferencias en el contexto jurídico) son procesos bi-direccionales, en los

${ }^{22}$ B. Bosanquet, Implication and Linear Inference. Londres: Macmillan, 1920 (reproducido por Nabu Press, 2010).

${ }^{23}$ Véase, por ejemplo, P. Thagard, Coherence in Thought and Action. Cambridge: MIT Press, 2000, pp.75-78 y L. BonJour, The Structure of Empirical Knowledge. Cambridge: Harvard University Press, 1985, pp. 89-93. 
que las premisas influencian las conclusiones al mismo tiempo que las conclusiones afectan la evaluación de las premisas ${ }^{24}$. La teoría coherentista que he avanzado en 'Diez Tesis' se basa en esta concepción holista de inferencia ya que sostiene que la justificación de un elemento depende de su coherencia con el resto y asume que las relaciones de coherencia son simétricas, de modo que dos elementos coherentes son mutuamente interdependientes, sin que uno se infiera del otro. La teoría no permite, por ejemplo, inferir, a partir de un conjunto de pruebas, una hipótesis explicativa, y luego inferir de esta hipótesis la aceptabilidad de un conjunto de pruebas en cuanto que resultan explicables por dicha hipótesis, sino que la teoría muestra que la aceptación de hipótesis acerca de los hechos (y del Derecho) y de proposiciones que describen pruebas (o elementos normativos) depende de su coherencia con el resto de elementos y cómo estos elementos están conectados entre sí por relaciones de apoyo mutuo o recíproco.

Una vez que entendemos que el modelo de inferencia 'tubular' ${ }^{25}$ o lineal, propio de los sistemas lógicos, no es el único viable -ni el más adecuado para dar cuenta de la justificación de creencias acerca de los hechos y del derecho- es posible resolver el problema de circularidad que parece afectar, fatalmente, a las teorías coherentistas de la justificación en general. La circularidad sólo surge si la relación de inferencia se entiende como unidireccional, pero, de nuevo, las relaciones de inferencia coherentista no son unidireccionales. El círculo no es vicioso, no porque sea lo suficientemente amplio o robusto sino porque no es, en realidad, un círculo. Como la conocida metáfora de la 'red' expresa con claridad, lo que hay no es una serie circular de razonamientos lineales, sino una densa red de elementos conectados entre sí por relaciones de soporte mutuo. La solución al regreso consiste, por lo tanto, en cuestionar la concepción lineal de inferencia que da lugar

${ }^{24}$ Para un resumen de los resultados empíricos, véase D. Simon, “A Third View of the Black Box: Cognitive Coherence in Legal Decision-Making", 71 The University of Chicago Law Review (2004).

${ }^{25}$ La expresión de un modelo 'tubular' ('pipe-line') de justificación es de Shogenji. Véase T. Shogenji, "The Role of Coherence in Epistemic Justification”, 79 (1) Australasian Journal of Philosophy (2001). 
a este problema -y a la aparente circularidad del razonamiento coherentista- en primer lugar.

(iii) Por último, Redondo cuestiona la capacidad descriptiva del modelo de inferencia coherentista. Un simple test, dice Redondo, parece mostrar que, en contra de lo que sostengo, la justificación de las conclusiones acerca de los hechos y del derecho, no se entiende como el coherentismo propone: mientras que las partes pueden impugnar una decisión judicial por falta de justificación en sentido lógico-deductivo o las conclusiones acerca de los hechos mostrando que no hay ningún argumento inductivo que conduzca a ellas, ¿Podrían las partes impugnar las conclusiones del juez demostrando que ellas no son el resultado de un proceso de abducción? O, ¿Podrían hacerlo sobre la base de que los jueces no respetan las restricciones (procedimentales o de resultado) que menciona Amaya?"26 La respuesta, según Redondo, es negativa y esto indica que el modelo de inferencia coherentista no es adecuado descriptivamente.

A pesar de la plausibilidad psicológica del modelo coherentista de inferencia -plausibilidad que, a la luz de los estudios empíricos disponibles, no parece estar (en el, desde luego, rápidamente cambiante estado de las ciencias cognitivas) en cuestión, es legítimo preguntarse si la preeminencia que el razonamiento coherentista tiene en los procesos de formación de creencias acerca del derecho y de los hechos, se refleja en los procesos públicos de justificación de decisiones jurídicas y, de manera más específica, si razones de coherencia explicativa, a diferencia de lo que Redondo sostiene, son relevantes cuando los operadores jurídicos 'ofrecen', ‘critican' o 'reivindican' una justificación. Tanto en relación a la argumentación acerca de cuestiones normativas como fácticas, los argumentos de tipo abductivo (bajo una interpretación coherentista según la cual la mejor explicación es la más coherente) juegan, me parece, un papel fundamental en la práctica jurídica.

Respecto del razonamiento acerca de hechos, las partes pueden -como, de hecho, hacen- argumentar que un veredicto de culpabilidad no

${ }^{26}$ C. Redondo, “Decidir en modo justificado", p. 79. 
está justificado ya que existe una explicación plausible de los hechos que es compatible con la inocencia o que la explicación de los hechos que implica la culpabilidad del acusado no es lo bastante buena como para justificar un veredicto de culpabilidad. Ronald Allen y Brian Leiter han examinado en detalle cómo un modelo explicacionista de argumentación acerca de los hechos describe importantes rasgos de la práctica jurídica norteamericana, pero sus conclusiones se pueden, me parece, extender de manera no problemática a otros sistemas jurídicos ${ }^{27}$. La falta de coherencia explicativa de la hipótesis acerca de los hechos que implica la culpabilidad del acusado -o la mayor coherencia con las pruebas disponibles, a la luz de un conjunto de creencias empíricas generales ampliamente aceptadas, de la hipótesis que implica su inocencia- figuran de manera central en la motivación de las sentencias judiciales, como cuando un juez argumenta que un veredicto de culpabilidad no está justificado porque no explica una parte substancial de las pruebas disponibles (principio 2 de la teoría de la coherencia explicativa) o porque no satisface el estándar de prueba aplicable al existir una explicación alternativa de los hechos (principio 7) o es contradictoria con ciertas proposiciones que describen pruebas admitidas a juicio (principios 4 y 5).

Los argumentos coherentistas juegan también un papel central en la justificación de las decisiones judiciales acerca de cuestiones normativas en el Derecho. Para empezar, negar la capacidad descriptiva de un modelo coherentista de justificación acerca de cuestiones normativas implicaría ignorar la relevancia que han tenido tradicionalmente los argumentos basados en principios o la analogía -que son tipos de argumentos, como bien ha explicado de manera detenida Neil MacCormick, de tipo coherentista- ${ }^{28}$ o el argumento ad absurdum -que apela a la idea de incoherencia en las argumentaciones tanto de las

${ }^{27}$ R. Allen y B. Leiter, "Naturalized Epistemology and the Law of Evidence", 87 Virginia Law Review (2001).

${ }^{28}$ N. MacCormick, Legal Reasoning and Legal Theory. Oxford: Clarendon Press, 1994, pp. 157-161 y Rhetoric and the Rule of Law: A Theory of Legal Reasoning. Oxford: Oxford University Press, 2005, capítulo 10. 
partes como de los jueces ${ }^{29} \mathrm{Y}$, con independencia de que uno subscriba o no la teoría de la justificación de la decisión judicial de Ronald Dworkin, no parece particularmente controvertido que el modo de operar del juez Hércules -que, como he mostrado en otro lugar, es de manera fundamental un razonamiento de tipo abductivo o explicativo- ${ }^{30}$ no es ajeno a la manera en la que los jueces razonan, al menos, en algunos casos difíciles ${ }^{31}$ Que un determinado principio explique un conjunto de decisiones relevantes (principio 2 de la teoría de la coherencia explicativa), que una interpretación sea coherente con la solución dada a casos análogos (principio 3), o que una determinada hipótesis interpretativa sea contradictoria (principio 5) son razones que, de manera habitual, se encuentran tanto en los razonamientos de las partes como en las justificaciones ofrecidas por los jueces. La inferencia a la mejor explicación (i.e., la interpretación más coherente) de un conjunto de elementos (bien fácticos, bien normativos) es, a diferencia de lo que sostiene Redondo, un patrón de inferencia central en las justificaciones tanto de jueces como de abogados.

\section{Respuesta a Aldo Schiavello. Coherencia $Y$ OBJETIVISMO}

Schiavello presenta tres objeciones fundamentales a la propuesta presentada en "Diez Tesis": i) La coherencia no es incompatible -a diferencia de lo que sostengo en este trabajo- con una concepción instrumental de racionalidad práctica; ii) La inferencia a la mejor explicación no permite identificar -apelando a criterios de coherencia- una explicación como la mejor, tan sólo permite identificar un conjunto de explicaciones aceptables; iii) La combinación de coherentismo y responsibilismo da lugar a un dilema: la noción de

\footnotetext{
${ }^{29}$ M. Atienza, Las razones del Derecho: Teorías de la argumentación jurídica. Madrid: Centro de Estudios Constitucionales, 1991, pp. 23-25.

${ }^{30}$ A. Amaya, The Tapestry of Reason: An Inquiry into the Nature of Coherence and its Role in Legal Argument. Oxford: Hart Publishing, en prensa, 2012, capítulo 1.

${ }^{31}$ R. Dworkin, Law's Empire. London: Fontana, 1986, pp. 240-254.
} 
responsabilidad epistémica o bien cumple un papel meramente retórico y es, por ello, irrelevante, o bien cumple una función restrictiva y, en este caso, es incompatible con la concepción interpretativa de coherencia defendida en este trabajo. Las tres objeciones, me parece, apuntan a un mismo problema: la supuesta asociación entre mi propuesta coherentista y una posición objetivista que resulta, a juicio de Schiavello, insostenible. Trataré de contestar a estas preguntas en el orden en el que se han presentado y clarificar, en el curso de mis respuestas, los presupuestos meta-éticos de mi propuesta.

(i) Según Schiavello, la coherencia -a diferencia de lo que sostengo en mi artículo, es compatible con una concepción instrumental de racionalidad práctica. En efecto, tiene razón Schiavello cuando señala que no existe una incompatibilidad entre una concepción coherentista de la justificación y una concepción instrumental de racionalidad práctica. Mi objetivo en "Diez Tesis" no es -y quizá no me haya expresado con suficiente claridad- sostener que el coherentismo sea incompatible con el instrumentalismo, sino defender la tesis según la cual el coherentismo nos proporciona algunas herramientas útiles para razones acerca de fines y valores. Pero es perfectamente posible sostener una concepción coherentista de justificación y una concepción instrumentalista de racionalidad práctica. En otras palabras, los métodos coherentistas nos brindan la posibilidad de razonar acerca de fines y valores y, por lo tanto, de expandir el ámbito de la racionalidad más allá de la evaluación de las relaciones medio-fin, pero aceptar una concepción coherentista de la justificación no implica necesariamente aceptar una concepción no instrumental de razón práctica.

La relación entre el coherentismo (acerca de la justificación) y el instrumentalismo (acerca de la razón práctica) dependerá de cómo se integre la base de la coherencia, es decir, de cuál sea el conjunto de elementos cuya coherencia confiere justificación. Por ejemplo, uno podría sostener que la coherencia nos permite restringir el conjunto de decisiones jurídicas justificables a aquéllas que son coherentes con el sistema jurídico, pero que la elección entre las mismas es una cuestión valorativa que se encuentra más allá del ámbito de la razón. Las 
concepciones coherentistas de la justificación jurídica de Neil MacCormick y de Aleksander Peczenick (al menos, en sus primeras formulaciones) son ejemplos de teorías de la coherencia según las cuales las razones de coherencia no nos permiten individualizar una determinada decisión como justificada. Por el contrario, la teoría coherentista de Ronald Dworkin, al incluir en la base de la coherencia razones de moralidad política, está asociada a una concepción de la razón práctica según la cual es posible razonar acerca de fines y valores $\mathrm{y}$, en último término, justificar -en base a razones de coherencia- el juicio de valor del que depende, en última instancia, la decisión. Por lo tanto, una concepción coherentista de la justificación no es incompatible con una concepción instrumental de razón práctica pero, a diferencia de concepciones alternativas de la justificación, puede también ponerse al servicio de una concepción no instrumental de razón práctica.

Schiavello, en su comentario, sostiene que el rechazo de una concepción instrumental de la racionalidad práctica implica una concepción objetivista fuerte según la cual habría una respuesta correcta en cada caso. Sin embargo, es posible defender que la razón práctica nos permite deliberar acerca de fines y valores sin comprometerse con la tesis de la única respuesta correcta. Por ejemplo, la teoría coherentista del razonamiento práctico defendida por Hurley -y que discute Schiavello- es una teoría según la cual la deliberación práctica no sólo consiste en evaluar la adecuación entre medios y fines sino que consiste, en ocasiones, en razonar acerca de fines y valores. Sin embargo, esta teoría contempla la posibilidad de que existan casos de indeterminación -es decir, situaciones en las que más de una teoría acerca de los fines y valores en conflicto sea igualmente coherente- así como casos de sobredeterminación- es decir, situaciones en las que ninguna de las teorías articuladas en el curso de la deliberación satisfacen los criterios de coherencia- ${ }^{32}$. No parece, por lo tanto, que aceptar una concepción no instrumental de razón práctica implique que todos los conflictos sean resolubles. Lo que sí implica es que la razón no nos deja desamparados

32 S. Hurley, Natural Reasons: Personality and Polity. Cambridge: Harvard University Press, 1989, capítulo 12. 
frente a los conflictos -incluso en casos en los que éstos son muy severos. La razón nos permite eliminar ciertas soluciones como no satisfactorias y, en ocasiones, determinar que una solución es la más satisfactoria, pero puede haber casos de conflicto que resistan solución. Una aproximación coherentista al razonamiento práctico nos proporciona una guía acerca de cómo podríamos proceder en casos de conflictos de valores sin asumir que en todos los casos de conflicto existe una única respuesta correcta.

(ii) Schiavello sostiene que no existe una explicación mejor en términos absolutos: la coherencia tan sólo nos permite identificar un conjunto de decisiones aceptables, entre las cuales el decisor elige a partir de una serie de preferencias personales de diversa índole que desafían cualquier análisis racional. Existe, dice Schiavello, una conexión esencial entre la coherencia y las intuiciones o las preferencias irracionales. En cada uno de los estadios que distingo en una inferencia a la mejor explicación -i.e. la generación del conjunto de elementos relevantes, la elaboración de un conjunto de hipótesis plausibles y la selección de una de ellas como justificada en base a criterios de coherencia- intervienen, de manera determinante, las preferencias valorativas del decisor.

Comparto con Schiavello la idea de que no existe una mejor explicación en términos absolutos, pero esto no implica, en último término, que la selección de una explicación como mejor dependa sin más de los juicios de valor subjetivos. Los juicios de relevancia, de plausibilidad y de coherencia que es necesario hacer para inferir que una explicación (de los hechos o del derecho) es la mejor, son, sin duda, relativos a un stock de conocimiento general. En este sentido, como cualquier otra forma de inferencia no deductiva, las inferencias a la mejor explicación dependen del contenido. Pero esto no significa que estos juicios sean una cuestión valorativa a resolver a la discreción del juzgador. Por ejemplo, cuando un juez o un miembro del jurado está tratando de determinar cuál es la mejor explicación de los hechos en un caso de asesinato, debe tomar en cuenta las creencias generalmente aceptadas acerca de cómo se cometen habitualmente los asesinatos, 
acerca de la motivación, de la causalidad, etc. Sin embargo, en casos de este tipo, no es posible concluir que la mejor explicación de los hechos es que la víctima fue asesinada por el espíritu de su mujer -muerta tras años de abuso- porque esto está en conflicto con creencias generalmente aceptadas acerca de las relaciones entre el mundo de los vivos y de los muertos, con independencia de que el decisor tenga o no creencias firmes acerca de la posibilidad de que los espíritus intervengan en asuntos humanos. Por lo tanto, un estándar coherentista limita el rol que pueden jugar los juicios de valor subjetivos, aunque, por supuesto, cualquier solución a la que arribemos siguiendo un método coherentista va a depender del estado del conocimiento actual y puede ser derrotable (por ejemplo, por investigaciones futuras acerca de la vida y la muerte...). Los juicios de coherencia son relacionales pero esto no los hace -y éste es el punto de desacuerdo- radicalmente subjetivos.

En apoyo de la tesis según la cual la individuación de la mejor explicación es una cuestión intuitiva y, por lo tanto, que escapa al control racional, Schiavello aduce el célebre caso de O.J. Simpson. Incluso -dice Schiavello- en un caso aparentemente fácil, como éste, el test de coherencia no permite identificar una explicación como la mejor. La decisión del jurado fue el resultado -y cita aquí Schiavello a Paul Thagard- de una combinación de coherencia explicativa y prejuicios emotivos. Aunque, como reconoce Schiavello, el hecho de que la coherencia no permita explicar la decisión del jurado no implica que una teoría coherentista no pueda, en principio, justificar el mismo, el caso de O.J. Simpson pone de relieve, a su juicio, la insuficiencia de los criterios de coherencia para identificar una explicación como la mejor y la necesidad de apelar a la intuición y a las preferencias irracionales del decisor. El razonamiento del jurado en este caso, sin embargo, como he tratado de mostrar en otro lugar, puede ser explicado en términos coherentistas $^{33}$. El veredicto del jurado no se corresponde con la explicación que satisface los criterios de coherencia propuestos por

\footnotetext{
${ }^{33}$ A. Amaya, "Inference to the Best Explanation in Law" en Legal Evidence and Proof: Statistics, Stories, Logic, editado por H. Kaptein, H. Prakken y B. Verheij. Farnham: Ashgate, 2009.
} 
Thagard porque estos criterios no tienen en cuenta que la evaluación de hipótesis explicativas en el Derecho tiene lugar en un contexto institucional que impone ciertas restricciones -tales como las derivadas de la presunción de inocencia o el estándar de la prueba-. Pero una vez que incorporamos estas restricciones, es posible mostrar que la decisión del jurado, lejos de ser el fruto de prejuicios o de la mera intuición, fue la decisión que mejor satisfacía los criterios de coherencia fáctica. Un análisis coherentista adaptado a la realidad institucional del derecho nos permite, por lo tanto, identificar una explicación como la mejor.

Que la conclusión de una inferencia a la mejor explicación pueda ser justificada en base a criterios de coherencia no excluye, por supuesto, la posibilidad de que, a la luz de nuevas pruebas o de la revisión del conjunto de creencias empíricas aceptado como justificado, surja otra explicación que derrote la explicación aceptada como mejor. La mejor explicación es siempre la mejor explicación de aquéllas que se han considerado. Lo que es esencial es que el decisor jurídico examine con el debido cuidado todas aquellas hipótesis que son relevantes a la luz de las creencias generalmente aceptadas y de las pruebas disponibles. La respuesta correcta o la mejor explicación que están fuera del alcance de un decisor jurídico que conduce sus actividades de investigación y deliberación de manera impecable carecen de relevancia práctica. Una concepción de justificación que tenga la capacidad de guiar la práctica y que pueda servir como un criterio útil de evaluación tiene que estar vinculada con aquello que, dados nuestros recursos cognitivos, conocimiento y habilidades, podemos llegar a hacer. Es aquí donde juega un papel central la noción de responsabilidad epistémica, objeto de la tercera y última crítica de Schiavello, que paso a examinar a continuación.

(iii) Según Schiavello, la combinación de coherentismo y responsibilismo que propongo da lugar a un dilema: o bien la noción de responsabilidad epistémica cumple meramente un papel retórico y es, por lo tanto, irrelevante, o bien cumple una función justificativa lo cual es, sostiene Schivello, incompatible con la tesis según la cual la coherencia es el producto de la interpretación. Me parece, desde luego, 
que la combinación de coherentismo y responsibililismo no está exenta de problemas ${ }^{34}$; sin embargo, no creo que el papel que juegan los estándares de responsabilidad epistémica en la teoría coherentista de la justificación propuesta en mi trabajo de lugar al dilema que plantea Schiavello. Por un lado, estos estándares limitan el modo en el que se puede construir la coherencia en el curso de los procesos de decisión jurídica y no cumplen, por lo tanto, una función meramente retórica. Desde luego, los estándares de responsabilidad epistémica son vagos en cierta medida -no se puede precisar mediante una regla cuándo el análisis de las pruebas es lo suficientemente cuidadoso o cuántas pruebas es necesario procurar para satisfacer el deber de buscar pruebas acerca de proposiciones dudosas o qué conductas es preciso realizar para considerar un caso con la debida apertura de mente -la determinación de estas cuestiones dependerá, entre otros factores, del contexto-. Pero la sensibilidad contextual de estos estándares no implica que los mismos puedan legitimar cualquier decisión ni que, como dice Schiavello, la noción de responsabilidad epistémica sea tan vaga que tan sólo pueda desempeñar un papel retórico, apoyando la decisión preferida del decisor. Retomemos el caso de O.J. Simpson, el cual, según Schiavello, evidencia la función meramente retórica de los estándares de responsabilidad epistémica. A diferencia de lo que sostiene Schiavello, no cualquier proceso de construcción de la coherencia es epistémicamente responsable $\mathrm{y}$, en este sentido, la noción de responsabilidad epistémica nos permite excluir ciertas hipótesis como injustificadas. Por ejemplo, un miembro del jurado que, en el caso de O.J., fuera incapaz de cuestionar sus creencias acerca de la honestidad de la policía, incluso a la luz de pruebas que indican la posibilidad de que hubo irregularidades serias en la investigación llevada a cabo por la policía, estaría siendo epistémicamente irresponsable. La mejor explicación de las consideradas por este miembro del jurado cuya fe

\footnotetext{
${ }^{34}$ Guillermo Lariguet, también encuentra problemática, por otras razones, la combinación de coherentismo y responsabilismo. Véase G. Lariguet, “Todo lo que Ud quería saber sobre la coherencia y no se atrevió a preguntarle a Amalia Amaya", así como mi réplica. He discutido algunos de los problemas que enfrenta una concepción de la justificación en términos de coherencia y responsabilidad epistémica en el capítulo 10 de The Tapestry of Reason.
} 
ciega en la policía le impide incluir en el conjunto de hipótesis a considerar la hipótesis de que la policía haya incriminado al acusado no gozaría de justificación ya que no es la mejor hipótesis del conjunto de hipótesis que un miembro del jurado epistémicamente responsable habría sometido a consideración.

Por otro lado, la tesis según la cual la coherencia confiere justificación si y sólo si es el resultado de un proceso responsable de formación de creencias no presupone una concepción objetivista incompatible con una concepción interpretativa de la coherencia. Sin duda, esta aproximación responsibilista a la justificación es incompatible con una concepción según la cual la interpretación es una actividad discrecional. El proceso orientado a la maximización de la coherencia es interpretativo pero de ahí no se sigue -y en este punto estoy en desacuerdo con Schiavello- que sea un proceso discrecional en cuanto que dependa, en último término, de la intuición y las elecciones valorativas del decisor. Pero el rechazo de la tesis subjetivista según la cual la construcción de la coherencia es el resultado de un proceso de interpretación "altamente" discrecional no implica la aceptación de la tesis objetivista según la cual la coherencia no se construye -se "encuentra"-. Dice Schiavello: "questa nozione [la noción de responsabilidad epistémica] sembra presupporre una qualche versione dell'oggettivismo meta-etico (monista). E come se si presupponesse l'esitenza dell'ipotsi più coerente e si attribuisse al decisore epistemicamente responsabile il compito di individuarla (non di construirla)" 35 . Por el contrario, según la concepción coherentista de la justificación jurídica defendida en "Diez Tesis", no es que haya una hipótesis coherente tal que el agente epistémicamente responsable tiene que individuarla, sino que una hipótesis está justificada en virtud de su coherencia si es una hipótesis que un agente epistémicamente responsable podría haber aceptado como tal. El papel de la responsabilidad epistémica -de la virtud- es, en este sentido, constitutivo de la justificación y no epistémico -es decir, no presupone que haya

\footnotetext{
${ }^{35}$ A. Schiavello, "Tre osservazioni su Diez tesis acerca de la coherencia en el Derecho", p. 177.
} 
criterios objetivos independientes de la práctica del virtuoso que nos permitan determinar cuál es la mejor respuesta en un caso concreto-. La introducción de la responsabilidad epistémica en una teoría coherentista de la justificación no es contradictoria, por lo tanto, con una concepción interpretativa de la noción de coherencia.

\section{Respuesta a Guillermo Lariguet. Coherencia y CONFLICTO}

El comentario de Lariguet aborda diversos problemas del coherentismo en general y de mi propuesta, en particular, tales como el problema de cómo articular de manera satisfactoria la relación entre coherencia y consistencia, las dificultades para conectar la coherencia con la verdad o los problemas relativos a la determinación del conjunto de elementos que constituyen el input de los métodos coherentistas. La mayor parte de su comentario versa sobre la relación entre coherencia y conflicto y en mis respuestas me voy a limitar a examinar esta cuestión que es, me parece, la que a Lariguet le resulta más apremiante. En concreto, trataré de responder a tres de las preguntas que, en relación a este tema, me plantea Lariguet: i) ¿Cómo se podrían resolver en mi propuesta los casos en los que más de un esquema de principios, igualmente coherente, nos permite explicar y justificar la práctica jurídica?; (ii) ¿Hasta qué punto se puede defender que una teoría de la coherencia recargada con una teoría de la virtud no elimina realmente el conflicto?; (iii) ¿Puede una teoría coherentista de la justificación como la propuesta aquí ser sensible a cierta dosis -beneficiosa, a juicio de Lariguet- de incoherencia?

(i) Una de las objeciones tradicionales a las teorías coherentistas de la justificación es la objeción según la cual estas teorías no permiten seleccionar entre distintos conjuntos de elementos igualmente coherentes. La objeción es igualmente seria en el caso de las teorías coherentistas de la justificación jurídica: ¿Cómo proceder en los casos en los que más de una decisión resulta ser igualmente coherente con el derecho? La respuesta a esta pregunta -y la gravedad de la 
objeción- dependerá del modo en que una teoría de la coherencia construya el conjunto de elementos que se consideran relevantes para la justificación de la decisión. Si uno expande la base de la coherencia incluyendo lo que -en una expresión muy afortunada- Lariguet llama "principios bisagra", es decir, principios que amalgaman moral y derecho así como principios de moralidad política, la relevancia práctica de las situaciones en las que el método coherentista nos deja desamparados se reduce considerablemente, al menos, en los estados constitucionales modernos.

Ahora bien, esta respuesta, plantea un problema adicional: si enriquecemos la base de la coherencia -el conjunto de elementos relevantes para evaluar la coherencia y, por lo tanto, la justificación, de una decisión jurídica- de modo que la misma incluya no sólo razones de autoridad sino también razones de moralidad política, entonces se corre el riesgo de que la teoría de la coherencia termine legitimando decisiones que no están conectadas de manera adecuada con las razones de autoridad. En otras palabras, la teoría de la justificación como coherencia no es adecuada ya que no da cuenta del papel que deben jugar las razones de autoridad en el derecho. Sin embargo, no hay ninguna razón por la cual una teoría de la coherencia no pueda reconocer el papel fundamental que juegan las razones de autoridad en la justificación jurídica. Tal y como he defendido en mi trabajo es posible avanzar una concepción "discriminadora" de coherencia para el derecho que otorgue un lugar privilegiado a las razones de autoridad en el cómputo de la coherencia ${ }^{36}$. Bajo esta concepción, una teoría de la coherencia descartaría como injustificada una decisión que no estuviera conectada de manera adecuada con las razones de autoridad.

\footnotetext{
${ }^{36}$ Las teorías discriminadoras de la coherencia dan prioridad a un subconjunto de elementos en el cómputo de coherencia (por ejemplo, las proposiciones que describen observaciones, en el caso de la coherencia explicativa), de manera que los mismos gozan de cierto grado inicial de aceptabilidad. Véase P. Thagard, C. Eliasmith, P. Rusnock, and C. P. Shelley, "Knowledge and Coherence" en Common Sense, Reasoning, and Rationality, editado por R. Elio. New York: Oxford University Press, 2002 y P. Thagard, Coherence in Thought and Action. Cambridge: MIT Press, 2000, p. 71.
} 
Pero, se pregunta Lariguet, ¿no resulta incompatible un modelo coherentista con el reconocimiento de que no todos los principios están en el "mismo nivel" sino que algunos de ellos son "básicos o fundamentales”? “¿No colapsa el modelo coherentista en un modelo subrepticiamente fundacionista?"37. Mi respuesta a estas preguntas es negativa. La introducción de un principio que reconozca el papel fundamental que juegan las razones de autoridad en la justificación jurídica no convierte a una teoría coherentista en una teoría fundacionista. La razón por la cual el coherentismo es compatible con la asignación de un estatus especial a ciertas razones dentro del conjunto de razones relevantes para justificar una determinada decisión tiene que ver con la importancia que tienen las creencias de segundo nivel en una teoría coherentista de la justificación ${ }^{38}$. La base de la coherencia no sólo incluye creencias de primer nivel acerca del derecho y la moralidad política sino también creencias acerca del peso relativo de estas creencias y de las relaciones entre las mismas. Son razones de coherencia, en último término, las que justifican la atribución de un peso especial a las razones de autoridad. Por lo tanto, la atribución de un peso especial a las razones de autoridad es compatible con el coherentismo.

En resumen, la objeción según la cual la teoría de la coherencia no proporciona una guía suficiente a los decisores jurídicos en todos aquellos casos en los que hay dos decisiones igualmente coherentes pierde relevancia práctica si aumentamos la base de la coherencia de modo que ésta incluya no sólo razones de autoridad sino también razones de moralidad política. Este movimiento, sin embargo, no hace que el coherentismo sea incompatible con la autoridad del derecho, puesto que es posible reconocer -desde una perspectiva coherentista, no fundacionista- el papel fundamental que juegan las razones de autoridad en la justificación jurídica. Desde luego, esta respuesta asume que es

\footnotetext{
${ }^{37}$ G. Lariguet, “Todo lo que Ud. quería saber sobre la coherencia y no se atrevió a preguntarle a Amalia Amaya" p. 97, cita 6.

${ }^{38}$ Las creencias de segundo nivel juegan también un papel fundamental en la discusión acerca del conservadurismo que caracteriza a las teorías de la justificación coherentista, como he sostenido en mi respuesta a Juliano Maranhão.
} 
posible razonar acerca de fines y valores: si uno acepta una tesis escéptica acerca de la moralidad, entonces, la inclusión de razones de moralidad política en la base de la coherencia no resuelve el problema de la indeterminación -en los casos en los que hay dos decisiones igualmente coherentes con el derecho vigente- sino que lo reproduce a otro nivel -en los casos en los que dos decisiones son igualmente coherentes con el derecho dado y un conjunto de valores de moralidad política. La respuesta es, no obstante, compatible tanto con la tesis según la cual los valores morales son conmensurables como con la tesis según la cual los valores morales son inconmensurables, siempre y cuando no se sostenga -de modo, a mi parecer, erróneo- que la conmensurabilidad es un requisito de la elección racional.

(ii) Nada de lo dicho hasta aquí implica que todos los conflictos normativos se puedan resolver apelando a la coherencia con un conjunto de razones jurídicas y morales. Sostener una actitud no escéptica frente a la posibilidad de razonar acerca de fines y valores no equivale a afirmar que, en todos los casos, es posible justificar la selección de una única respuesta correcta y que, por lo tanto, el conflicto normativo es siempre resoluble ${ }^{39}$. Sin embargo, a juicio de Lariguet, ésta es precisamente la conclusión que se sigue si "recargamos" la teoría de la coherencia con una teoría de la virtud, tal y como propongo en mi trabajo. La combinación de coherencia y virtud tiene como resultado la eliminación del conflicto ya que el virtuoso siempre -“casi siempre"- encontrará la respuesta correcta. Esta interpretación de la idea de virtud no es una tesis sostenida por la mayoría de los defensores de la teoría de la virtud y no es, en cualquier caso, la interpretación que yo pretendo defender. Como señala McDowell, el agente virtuoso tiene las capacidades necesarias para identificar la respuesta correcta en el caso de que haya una pero esto no implica que siempre -ni siquiera "casi siempre"- haya una respuesta correcta o que siempre exista una manera de actuar de modo

\footnotetext{
${ }^{39}$ Sobre este punto, véase también la introducción de Manuel Atienza y el comentario de Aldo Schiavello así como mi réplica.
} 
satisfactorio ${ }^{40}$ En este sentido, la tesis según la cual la virtud cumple una función importante en una teoría de la justificación no implica negar la existencia de casos dilemáticos. Incuso es posible que haya, en algunos casos de conflicto normativo severo, desacuerdo entre los virtuosos. El hecho de que haya desacuerdo en algunos casos no significa que la teoría de la virtud sea incapaz de guiar la acción o que permita legitimar cualquier decisión en estos casos. El juez virtuoso procederá frente a los dilemas de una cierta manera -lo que circunscribe de manera importante el tipo de respuestas justificadas- pero no reduce la indeterminación al punto de identificar una única respuesta correcta.

La resolución virtuosa de casos que presentan dilemas, como los que preocupan a Lariguet, podría caracterizarse del modo siguiente -me limito, desde luego, simplemente a esbozar los rasgos generales de este proceso ${ }^{41}$. En primer lugar, el agente virtuoso tiene la capacidad de reconocer que se está enfrentando a un dilema moral, es decir, tiene la capacidad de reconocer que el caso afecta de manera central a valores fundamentales y que el conjunto de razones relevantes apoyan decisiones incompatibles de manera que, se tome el curso de acción que se tome, se sacrificará algo valioso. En segundo lugar, tratará de encontrar una salida entre los cuernos del dilema y encontrar una solución que evite lesionar un valor fundamental. El juez dotado de sabiduría práctica se esforzará por elaborar la mejor teoría posible acerca de cómo los distintos valores en conflicto se relacionan entre sí con el objetivo de determinar el mejor curso de acción a seguir. En tercer lugar, el juez, una vez que haya determinado cómo hacer, como dice McDowell, "lo mejor de un mal trabajo" 42 considerará los distintos medios para llevarlo a cabo, con el objetivo de elegir aquél que sea menos pernicioso. Por último, el juez virtuoso, tendrá una respuesta emocional apropiada a la realización de una acción de esa naturaleza.

${ }^{40}$ J. McDowell, "Virtue and Reason", en Mind, Value, and Reality. Cambridge: Harvard University Press, 1998, p. 53, n. 5.

${ }^{41}$ R. Hursthouse, "Two Ways of Doing the Right Thing", en Virtue Jurisprudence, editado por C. Farrelly y L. B. Solum. New York: Palgrave Macmillan, 2008.

${ }^{42}$ J. McDowell, "Virtue and Reason", en Mind, Value, and Reality. Cambridge: Harvard University Press, 1998, p. 53, n. 5. 
Por lo tanto, la idea de virtud, que es, según he defendido, un complemento necesario para una teoría coherentista de la justificación, no implica que la misma termine erradicando el conflicto, pero sí nos proporciona una guía acerca de cómo proceder racionalmente frente al mismo.

(iii) Me parecen francamente interesantes las observaciones de Lariguet acerca de las virtudes de la incoherencia. Cierta dosis de incoherencia, sostiene Lariguet, es positiva en cuanto que nos permite "ver cosas que una estructura -presuntamente- coherente no nos permitiría ver", como, por ejemplo, la existencia de un tratamiento jurídico-político asimétrico de cierta clase social, la existencia de conflictos de valores irresolubles, el potencial transformador de algunos cambios radicales o el valor del disenso ${ }^{43}$. Detrás del discurso coherentista, según Lariguet, casi siempre hay un "discurso del consenso uniforme", bien de facto bien como un ideal regulativo a satisfacer. ¿Hay un lugar para cierta dosis de incoherencia en un modelo coherentista? ¿Es posible respetar el disenso dentro de un orden coherente?

Estoy plenamente de acuerdo con Lariguet en que cierto grado de incoherencia puede ser beneficioso. Particularmente atractivas son sus sugerencias en relación al valor epistémico de tales incoherencias y, de manera más específica, al modo en que ciertas dosis de incoherencia facilitan la percepción de rasgos centrales del orden social. Aunque la incoherencia -obviamente- no ha tenido un lugar destacado en las teorías coherentistas de la justificación -tanto en el Derecho como en otras disciplinas- el valor de cierto grado de incoherencia no ha pasado totalmente desapercibido. Algunos de los defensores más prominentes de teorías coherentistas del razonamiento práctico han abogado por la tesis según la cual hay buenas razones para perseguir tan sólo cierto grado de coherencia dentro de nuestro sistema de fines y valores. Por ejemplo, según Richardson, cierto grado de coherencia es importante tanto para la coordinación intrapersonal como para la coordinación interpersonal,

\footnotetext{
${ }^{43}$ G. Lariguet, "Todo lo que Ud. quería saber sobre la coherencia y no se atrevió a preguntarle a Amalia Amaya", p. 125. 
pero la unificación de un sistema de fines personales y sociales no siempre es beneficiosa, ya que la diversidad es también un valor importante. Otros argumentos a favor de que nuestros sistemas de fines sean coherentes, como el argumento según el cual hay una conexión importante entre la coherencia y la felicidad, también apoyan tan sólo un grado moderado de coherencia, puesto que -siempre según Richardsonla exigencia de un fuerte grado de coherencia no se compagina bien con nuestra idea de felicidad ${ }^{44}$. De manera similar, Thagard y Millgram sugieren que aunque es deseable que nuestras inferencias prácticas aumenten la coherencia entre nuestros sistemas de fines, hay límites al grado de coherencia que parece deseable, ya que aumentar la coherencia, aumenta también la fragilidad -cuando todo 'encaja' a la perfección, si algo va mal, todo el sistema se desmorona al mismo tiempo- por ello, es preferible que nuestros sistemas de fines y valores satisfagan tan sólo cierto grado de coherencia a que los mismos se encuentren totalmente unificados $^{45}$. Algunos defensores de teorías coherentistas de la justificación han llegado incluso a defender directamente el valor de la incoherencia en ciertos contextos. Por ejemplo, Thagard menciona la incoherencia entre los factores que contribuyen de manera efectiva a la constitución del conjunto de elementos relevantes para la justificación: en ocasiones, la dificultad de hacer una interpretación coherente nos lleva a generar nuevas hipótesis y a procurar nuevas pruebas ${ }^{46}$. En relación a la justificación de creencias no empíricas sino morales, DePaul ha argumentado a favor de la importancia de las "conversiones morales", es decir, los cambios discontinuos de creencias morales que no están ni determinadas ni requeridas por el sistema de creencias previo del individuo ${ }^{47}$.

Sostener que la coherencia es central en una teoría de la justificación es, a la luz de estos ejemplos, compatible con el

${ }^{44}$ H. Richardson, Practical Reasoning about Final Ends. Cambridge: Cambridge University Press, 1994, pp. 156-7.

${ }^{45}$ Véase P. Thagard y E. Millgram, "Deliberative Coherence", 108 Synthese (1996), p. 67.

${ }^{46}$ P. Thagard, Coherence in Thought and Action. Cambridge: MIT Press, 2000, p. 67.

${ }^{47}$ M. DePaul, Balance and Refinement: Beyond Coherence Methods of Moral Inquiry. London: Routledge, 1993, pp. 40-41. 
reconocimiento de que hay límites al grado de coherencia deseable. La incoherencia cumple una función importante en cuanto que revela 'fallas' de nuestro sistema de creencias: como la incapacidad de una teoría científica de dar cuenta de ciertas observaciones sorprendentes, la dificultad de una concepción acerca de la moral de explicar ciertas intuiciones morales incómodas para la teoría, o la necesidad de revisar la interpretación de ciertos principios jurídicos cuyas consecuencias nos parecen indeseables, a la luz de otros fines y valores que consideramos importantes. Incluso, puede ser beneficioso tolerar cierto grado de incoherencia en nuestros sistemas de creencias: por ejemplo, es preferible, en ocasiones, aceptar una teoría científica novedosa, al menos provisionalmente, aunque tenga ciertas inconsistencias, que no tener ninguna, o que (lo que quizá sea más importante) aferrarse a una teoría científica que goza de un grado menor de coherencia explicativa, aunque sea consistente. Aprovecho aquí para contestar una pregunta que formula Lariguet respecto a cómo se relacionan la coherencia y la consistencia. La última no es una condición necesaria de la primera: un conjunto puede ser coherente aunque haya algunas inconsistencias, a pesar de que la coherencia necesaria para satisfacer el umbral de justificación no tolera cualquier número de inconsistencias ni inconsistencias entre cualquiera de los elementos del sistema. En este sentido, la coherencia exige, esto sí, cierto grado de consistencia. Por lo tanto, un orden coherente no necesita -y abordo aquí otro de los interrogantes que me plantea Lariguet- satisfacer condiciones tan fuertes como las que establece Kress (consistencia, completud, unidad, etc.). Es más, una teoría coherentista de la justificación no sólo permite acomodar cierto grado de incoherencia, sino que también nos permite dar cuenta incluso de cambios radicales, tales como las conversiones morales o las revoluciones científicas -como DePaul y Thagard, respectivamente, han mostrado, a mi juicio, convincentemente ${ }^{48}$.

La incoherencia, por lo tanto, me parece valiosa en tanto que a) nos permite cuestionar el sistema de creencias aceptado apuntando a

${ }^{48}$ M. DePaul, Balance and Refinement: Beyond Coherence Methods of Moral Inquiry. London: Routledge, 1993 y P. Thagard, Conceptual Revolutions. Princeton: Princeton University Press, 1992. 
posibles 'fallas' del mismo, y b) nos impulsa, en casos extremos, a reemplazar completamente el sistema de creencias aceptado como justificado en un determinado ámbito ${ }^{49}$. No obstante, la incoherencia deja de ser valiosa cuando no actúa como un motor de cambio que nos impulsa a revisar el orden aceptado o incluso a buscar un nuevo orden más coherente -como ocurre, por ejemplo, en las revoluciones científicas- sino que pasa a ser un 'rasgo' aceptado de nuestros sistemas de creencias. Al igual que las crisis económicas, éstas pueden ser beneficiosas a largo plazo si motivan el ajuste del orden económico para resolver problemas que la crisis ha sacado a la luz o incluso la substitución de un orden económico por otro, pero no cuando se vive 'en crisis' y éstas dejan de ser algo que hay que solucionar para convertirse en algo con lo que hay que convivir. Renunciar a la coherencia de nuestros sistemas de creencias (acerca del mundo, la moral, o el derecho) implica, como sostuvo Hurley, renunciar a nuestra identidad como agentes ${ }^{50}$. La coherencia tiene un valor constitutivo de la identidad -individual y social- que se vería seriamente comprometida si uno aceptara -se resignara- a vivir en la incoherencia. De nuevo, la coherencia que tiene valor justificativo es aquélla que se logra de un modo epistémicamente responsable, lo que exige, entre otras cosas, esforzarse por detectar las posibles incoherencias y revisar, a veces incluso de manera radical, las creencias a la luz de las mismas. La coherencia que es el resultado de impulsos totalizadores y que se logra a base de ignorar -o suprimir- las alertas que suponen las posibles incoherencias o inconsistencias carece de valor justificativo. La "sensibilidad a una cierta dosis de incoherencia" -en palabras de Lariguet- es una marca de la responsabilidad epistémica que, según he argumentado, es, a su vez, un componente esencial de una teoría coherentista de la justificación.

${ }^{49}$ Obviamente, no es posible cuestionar a la vez todo el sistema de creencias. Véase O. Neurath, "Protocol Sentences" en Logical Positivism, editado por A. J. Ayer. New York: The Free Press, 1959. Véase también E. Sosa, “The Raft and the Pyramid" en Knowledge in Perspective. Cambridge: Cambridge University Press, 1991, p. 169.

50 S. Hurley, Natural Reasons: Personality and Polity. Cambridge: Harvard University Press, 1989, pp. 260-263. 


\section{Respuesta a Claudio Michelon. Coherencia, VIRTUD Y RACIONALIDAD}

La discusión de Michelon se centra en dos problemas, a saber, el problema del valor de la coherencia y el problema de la insuficiencia de la misma como criterio de racionalidad. En relación al primer problema, Michelon sostiene que los argumentos presentados en mi artículo no son suficientes para justificar el valor de la coherencia como criterio de racionalidad. Según Michelon, la mejor manera de justificar el valor de la coherencia en el ámbito de la razón práctica es apelando a una concepción narrativa de la vida humana conforme a la cual la posibilidad de que las acciones de un agente se conduzcan a una determinada concepción del bien es un requisito para que éste pueda realizarse moralmente.

Me parece que la propuesta de Michelon de fundamentar el valor de la coherencia apelando a una concepción narrativa de vida humana no se contrapone a mi análisis de las razones por las cuales la coherencia tiene fuerza justificativa. Por el contrario, la relevancia de concebir una vida de forma narrativamente unitaria está íntimamente vinculada con lo que he llamado, siguiendo a Hurley, razones 'constitutivas' a favor de la coherencia, es decir, la idea de que la coherencia es valiosa en cuanto que es un elemento constitutivo de la identidad personal. Esta identidad, como he sostenido, se construye a través de la búsqueda de coherencia entre los distintos valores e intereses que consideramos importantes: la deliberación es, por lo tanto, un ejercicio de auto-interpretación y auto-determinación. De manera similar, Michelon señala que la importancia de concebir una vida de forma narrativamente coherente tiene un correlato psicológico en la búsqueda de sentido a través de una constante interpretación de nosotros mismos con el objetivo de articular una concepción compleja del bien que englobe una pluralidad de bienes y valores. Por lo tanto, tanto la concepción narrativa como la constitutiva apuntan a dos ideas centrales: la idea de que los humanos valoran una pluralidad de bienes y la idea de que la posibilidad de integrar los mismos en una concepción coherente es una condición para ser un agente moral. Ambas comparten también 
la idea de que la deliberación acerca de qué hacer -acerca de cómo resolver un determinado conflicto de valores- es, por ello, una deliberación acerca de quiénes somos o qué tipo de personas queremos ser. En resumen, la concepción de la coherencia según la cual ésta es un elemento central para la agencia moral está en la base tanto de la justificación narrativista como de la justificación constitutiva del valor de la misma. No parece, en este sentido, que haya ninguna diferencia substancial entre la tesis de Michelon acerca del valor de la coherencia y la que defiendo en 'Diez Tesis'. Teniendo en cuenta que, en este punto, Michelon usa como fuente a Charles Taylor y yo cito a Susan Hurley, esto no parece sorprendente.

Dice Michelon, sin embargo, que la defensa narrativista de la coherencia apunta a la necesidad de una antropología filosófica (i.e., una teoría del bien) que encaja bien con una concepción metafísica realista que yo considero poco plausible. No estoy, sin embargo, segura, y aquí estoy elucubrando acerca de la posición metafísica de Michelon (y, tengo que reconocer, también acerca de la mía) de que haya tampoco, en este punto, una divergencia importante. Si la defensa del valor de la coherencia requiere una metafísica realista, no se trata, en ningún caso, de una metafísica 'platónica' (que se fundamenta en una división tajante entre mente y mundo) sino de una metafísica naturalista, podríamos decir, 'aristótelica,' según la cual mente y mundo son interdependientes. La articulación de una concepción objetivista del valor moral, de una metafísica realista, en este sentido de realista, es un proyecto con el que Taylor y Hurley están firmemente comprometidos y con el que tanto Michelon (me aventuro a decir) como yo, simpatizamos ampliamente.

Pasemos ahora al segundo problema, el de la insuficiencia de la coherencia como criterio de racionalidad. En relación a este problema, es necesario -dice Michelon- distinguir entre dos cuestiones, la del control del abuso de los mecanismos de coherencia por parte del agente y la del control racional de la decisión. Respecto de la cuestión del control del agente, mi sugerencia de complementar el criterio de coherencia con un criterio de responsabilidad epistémica, entendida en base a virtudes presupone, de manera equivocada, a juicio de Michelon, 
que no hay, en una ética de las virtudes, un espacio conceptual para los deberes. Es posible también apelar a la idea de virtud para atacar la cuestión del control de la decisión, pero esta vía, según Michelon, no es muy prometedora y, en cualquier caso, no parece ser la tesis defendida en 'Diez tesis', ya que, en este trabajo, se introduce la concepción aretaica de responsabilidad epistémica para abordar el problema del control del decisor y no el problema del control de la decisión.

Empecemos por el problema de identificar los criterios que permiten el control del abuso de los mecanismos de coherencia por parte del decisor. Es necesario -y en esto está de acuerdo Micheloncomplementar el criterio de coherencia con otros criterios de racionalidad, para evitar que teoría de la coherencia termine legitimando decisiones cuya coherencia no es sino el resultado de procesos defectuosos de formación de creencias, por ejemplo, procesos que sufren de dogmatismo, prejuicio o descuido. El agente que concluye que la mejor explicación de los hechos es E pero sólo porque es incapaz de considerar la posibilidad de que E' sea una mejor explicación de los hechos -debido a que E' está en conflicto con un conjunto de creencias que el agente no está dispuesto a cuestionar- o porque ha evaluado de manera distorsionada los argumentos a favor de E y E' o porque, por pereza o negligencia, no procura ni considera pruebas que apoyan E' no está justificado en aceptar E. En otras palabras, sólo el razonamiento coherentista epistémicamente responsable confiere justificación. Michelon, sin embargo, sostiene que la responsabilidad epistémica no se debe entender exclusivamente en términos de virtudes, como defiendo en el trabajo objeto de comentario, sino también en términos de deberes.

Es importante clarificar que aunque la noción de deber no figura en mi definición de responsabilidad epistémica, no pretendo sostener que los deberes sean irrelevantes para determinar cuándo un agente se comporta de manera epistémicamente responsable. No es necesario, me parece, hacer una referencia explícita a la noción de deber porque la misma es redundante: va de suyo que un agente epistémicamente virtuoso cumplirá, en la mayor parte de las ocasiones, sus deberes epistémicos -aunque, puesto que es un agente virtuoso, sabrá 
determinar cuándo, a la luz de las circunstancias particulares del caso, la norma que impone deberes no debe, de manera excepcional, aplicarse. Empleando la útil distinción introducida por Michel on en su comentario entre versiones 'fuertes' y versiones 'débiles' de la ética (o la epistemología) de la virtud, la versión defendida en mi trabajo sería una versión débil, i.e., una versión que afirma que no es posible reducir las virtudes a conjunto de deberes pero que esto no excluye la utilidad de identificar los mismos. Al definir los estándares de responsabilidad epistémica exclusivamente en términos de virtudes, mi intención no es sostener una versión fuerte según la cual una ética de virtudes es incompatible con la asi gnación de valor a la noción de deber.

Sin embargo, el rechazo de una versión fuertetodavía dejasin contestar una pregunta, esencial, acerca de cómo se relacionan la ética de la virtud y la ética deontológica, a saber, la desi nociones irreducibles de deber y de virtud deben figurar en un esquema conceptual plural de Ia moral o si, por el contrario, la ética debe concebirse, como lo ha sido tradi cional mente, demanera monolítica-por ejemplo, en basea una ética delas virtudes que reconoce que los deberes juegan un papel importante, aunque derivado, en la moralidad. Tanto la versión fuerte como la versión débil, tal y como las define Michelon, parecen abogar por una concepción monista de la moral. Obviamente, la versión fuerte se inscribe en esta concepción ya que afirma que hay una contraposición entre éticas deontológicas y éticas de la virtud -o bien se defiende que la ética es, de principio a fin, una cuestión de deberes o bien se defiende que la misma se puede expl icar en su totali idad en términos de virtudes. Pero la versión débil también asume una concepción monista ya que aunque, según Michelon, en esta versión "no hay competencia entre dos concepciones éticas rivales" sí que hay "cooperación entre dos instrumentos (deberes y virtudes) al interior dela ética delas virtudes" 51 . En úl timo término, por lo tanto, incluso la versión débil conci bela ética de forma monista, como un sistema basado en virtudes, dentro del cual se le da un papel -secundario y derivado- a los deberes.

${ }^{51}$ C. Michelon, “Las razones de la coherencia”, p. 153. Énfasis añadido. 
En trabajos anteriores, he sostenido, sin embargo, que una concepción plausible de los estándares de responsabilidad epistémica debe coordinar nociones irreducibles de valor junto con nociones irreducibles de deber -en otras palabras, he abogado por una concepción no monolítica de la ética. Es dudoso, sin embargo, que se pueda defender una posición ecléctica de manera coherente (algo que es siempre importante, pero, uno diría, imperativo en el contexto de un trabajo sobre coherencia...). Por este motivo, he tratado de explorar la posibilidad de desarrollar una concepción de la responsabilidad de los decisores jurídicos que dé a las virtudes un lugar prioritario. Pero he de reconocer que no tengo una posición firme respecto a cómo se deben relacionar una ética de la virtud con una ética deontológica. Una versión fuerte que lleve a eliminar la noción de regla o deber me parece insostenible, pero hay diversas alternativas, inicialmente plausibles, acerca del papel que estas nociones pueden jugar en una concepción bien plural bien monolítica de la ética (y la epistemología). Sin embargo, la deter-minación de cuál es la mejor manera de entender esta relación nos aleja ya de discusiones acerca del coherentismo para adentrarnos de lleno en cuestiones propias de la teoría de la virtud.

El análisis de la segunda cuestión que, según Michelon, es importante examinar a la hora de atacar el problema de la insuficiencia de la coherencia -la del control de racionalidad de la decisión- también nos lleva, en último término, a considerar asuntos centrales de la teoría de la virtud, más que, específicamente, de la teoría de la coherencia. Empiezo, de nuevo, con una aclaración. Dice Michelon que no parece que mi pretensión sea la de usar la noción de sujeto virtuoso como criterio de racionalidad, complementario al de coherencia, de las decisiones. Sin embargo, esto es justamente lo que trato de hacer: proponer un test contrafáctico para determinar la justificación de las decisiones según el cual una decisión está justificada si es una decisión que un agente epistémicamente responsable podría haber aceptado en virtud de su coherencia (o, lo que es lo mismo, si podría ser el resultado de un razonamiento coherentista virtuoso). En este sentido, el modelo de justificación que 
ofrezco, como bien señala Redondo ${ }^{52}$, pretende ser tanto un modelo de justificación procedimental como un modelo de justificación del resultado, ya que trata de dar cuenta de las condiciones bajo las cuales un agente está justificado en tomar una decisión (i.e. si ésta resulta de un proceso coherentista virtuoso) como de las condiciones bajo las cuales una decisión está justificada (i.e. si ésta podría ser el resultado de un proceso coherentista virtuoso).

Conforme al modelo de justificación de resultado propuesto, la virtud juega un papel constitutivo de la justificación (es una condición necesaria, y junto con la coherencia, suficiente para la justificación). Es decir, entre varias explicaciones igualmente coherentes, la decisión justificada es aquélla que tomaría un juez virtuoso precisamente, y esto es crucial, porque es la decisión que tomaría un juez virtuoso. La virtud puede, sin embargo, cumplir también otras funciones en una teoría de la justificación jurídica ${ }^{53}$. Por ejemplo, se le puede asignar a la virtud un papel epistémico, en lugar de un papel constitutivo, y sostener que la virtud no es una condición de justificación sino un criterio de justificación, de modo que lo que haría un juez virtuoso es el mejor criterio para determinar qué decisiones están justificadas pero lo que las hace justificadas no es que un juez virtuoso las tomaría sino razones independientes de la virtud (por ejemplo, la coherencia u otros criterios como, entre otros, el criterio de no circularidad que propone Michelon). Parece necesario examinar con cuidado las distintas maneras en las que la virtud puede ser relevante para una teoría de la justificación antes de concluir -como he sostenido en 'Diez Tesis'- que la misma debe figurar en el análisis del concepto de justificación. De nuevo, mi conclusión aquí, alcanzada en el contexto de desarrollar un modelo coherentista de la justificación, es tentativa. La evaluación de la plausibilidad de las distintas tesis que se pueden defender (radicales o moderadas, constitutivas o epistémicas) acerca del papel que juega la virtud en la justificación y, en concreto, en la justificación jurídica es ya un tema de

${ }^{52}$ C. Redondo, "Decidir en modo justificado".

${ }^{53}$ He tratado esta cuestión de manera más detallada en "The Role of Virtue in Legal Justification", Virtue, Law and Justice, editado por Amalia Amaya y Ho Hock Lai. Oxford: Hart Publishing, Oxford, en prensa, 2012. 
estudio propio de la teoría de la virtud y no de la teoría de la coherencia. Mi trabajo sobre coherencia espero que haya puesto, al menos, de manifiesto, que existen conexiones importantes entre una epistemología coherentista y la epistemología de la virtud -el análisis detallado de esta última tiene que quedar, sin embargo, para un trabajo futuro. 